\title{
Inspiratory muscle endurance in patients with chronic heart failure
}

John T Walsh, Richard Andrews, Paula Johnson, Louise Phillips, Alan J Cowley, William J M Kinnear

\begin{abstract}
Objective-To assess the significance of changes in respiratory muscle endurance in relation to respiratory and limb muscle strength in patients with mild to moderate chronic heart failure using a threshold loading technique.
\end{abstract}

Subjects-20 patients with chronic heart failure (17 male) aged 63.8 (SD 7.4) years and 10 healthy men aged $63.1(5 \cdot 6)$ years. Heart failure severity was New York Heart Association (NYHA) grade II (n = 11) and NYHA grade III/IV $(n=9)$.

Methods-Respiratory muscle strength was measured from mouth pressures during maximum inspiratory effort (MIP) at functional residual capacity (FRC) and limb muscle strength was measured using a hand grip dynamometer. Inspiratory muscle endurance was measured using a threshold loading technique. The total endurance duration, the maximum threshold pressure achieved (P-Max), and the inspiratory load (\% ratio of $P$ Max/MIP) were recorded in all subjects.

Results-Inspiratory muscles were weaker in patients with heart failure than in the controls [MIP 53.6 (16.5) $v$ 70.9 (20.2) $\left.\mathrm{cm} \mathrm{H}_{2} \mathrm{O}, \mathrm{P}<0.05\right]$. Hand grip strength was similar in both subject groups [31.6 (SD) $v$ 36.1 (15.9) dynes]. Total endurance duration was significantly reduced in the patient group [494 (223) $v 996(267) \mathrm{s}, \mathrm{P}<0.011$, as was the maximal threshold pressure achieved [P$\operatorname{Max} 18.5(6.4) v 30.7(6.6) \mathrm{cm} \mathrm{H}_{2} \mathrm{O}, \mathrm{P}<$ $0.01]$. When expressed as a percentage of MIP, P-Max was also lower in the patients [35.2 (11.8) v $44.8(11.4) \%, P<$ $0 \cdot 05]$. There was no significant correlation between any measure of endurance and limb muscle strength.

Department of Cardiovascular Medicine, University Hospital, Nottingham J T Walsh

$R$ Andrews

P Johnson

Department of Respiratory Medicine, University Hospital, Nottingham L Phillips A J Cowley W J M Kinnear Correspondence to: Dr John Walsh, Department of Cardiology, Papworth of Cardiology, Papworth Campital, Papworth Evera Cambridge CB3 8
United Kingdom. Accepted for publication 8 May 1996

Conclusions-Respiratory muscle endurance is reduced in patients with chronic heart failure. These changes probably reflect a generalised skeletal myopathy and provide further evidence of respiratory muscle dysfunction in patients with this disease. Respiratory muscle endurance needs now to be related to symptoms and the effects of treatment and respiratory muscle training should also be explored.

(Heart 1996;76:332-336)

Keywords: respiratory muscles; chronic heart failure; endurance.
Fatigue and dyspnoea on exertion are common symptoms in patients with chronic heart failure. These symptoms often correlate poorly with measures of ventricular function, and the underlying mechanisms are unknown. ${ }^{1-3}$ Studies of skeletal limb muscle suggested that abnormal muscle function and metabolism are important contributory factors, ${ }^{4-7}$ which has led to a small number of studies of respiratory muscle function in patients with chronic heart failure. . $^{8-13}$

Respiratory muscle strength assessed in mouth pressure studies is reduced in patients with heart failure, but the clinical relevance of these findings is unclear.$^{8-13} \mathrm{~A}$ more appropriate study of muscle function in relation to exercise intolerance is measurement of endurance, defined as the ability of muscle to resist fatigue. Increased respiratory muscle endurance is associated with increased maximum and submaximal exercise capacity, with recent data to suggest that endurance can be improved by selective respiratory muscle training alone. ${ }^{14}$

As with many of the measures of exercise capacity in patients with chronic heart failure, assessment of endurance depends on the methods used. Maximum sustainable ventilatory capacity during isocapnic hyperpnoea has been described in these patients, but threshold loading of the inspiratory muscles is a useful alternative technique. ${ }^{15-19}$ This is a simple, reliable measure of respiratory muscle endurance that has not previously been described in patients with heart failure.

The aim of this study therefore was to determine whether respiratory muscle endurance, measured using a threshold loading device, is reduced in patients with mild to moderate chronic heart failure and if so whether this reduction reflected a generalised myopathic state.

\section{Methods}

PATIENTS

Twenty patients (three female, 17 male) with stable chronic heart failure entered the study over a six month period. Heart failure was due to ischaemic heart disease in 14 patients, dilated cardiomyopathy in four patients, and valvar heart disease in the remaining two. The mean duration of symptoms was $1 \cdot 8$ (SD $0 \cdot 2$ ) years. All patients had cardiomegaly on chest radiography (cardiothoracic ratio greater than $0.5)$ and echocardiographic evidence of impaired left ventricular function (defined as increased left ventricular end diastolic volume 
greater than $5.5 \mathrm{~cm}$, fractional shortening less than $20 \%$, and/or ejection fraction less than $35 \%)$. All were receiving diuretics (at least 40 $\mathrm{mg}$ of frusemide or equivalent) and angiotensin converting enzyme inhibitors. No other concomitant therapy was permitted. One patient was in New York Heart Association (NYHA) functional class IV, eight patients in class III, and the remaining 11 in class II. Serum potassium was normal in all patients. Those with recent respiratory tract infection or previous respiratory or neuromuscular disease were excluded.

Ten age matched normal controls also entered the study. None had a significant past medical history and all had a normal electrocardiogram, echocardiogram and chest $x$ ray.

The study was approved by the hospital ethics committee and all subjects gave informed consent.

\section{LUNG VOLUMES}

These were measured in all patients before entering the study. Forced expiratory volume in one second $\left(\mathrm{FEV}_{1}\right)$ and forced vital capacity (FVC) were measured with a bellows spirometer (Vitalograph, Buckingham, UK). Functional residual capacity (FRC), residual volume (RV), and total lung capacity (TLC) were measured by helium dilution (PK Morgan, Gillingham, Kent, UK).

\section{RESPIRATORY MUSCLE ENDURANCE}

Respiratory muscle endurance was measured with a pressure threshold valve during a $2 \mathrm{~min}$ incremental loading protocol as described by Martyn et al. ${ }^{18}$ Using a weighted inspiratory plunger all subjects began inspiration at a low load $(100 \mathrm{~g})$ and $100 \mathrm{~g}$ weights were then added at $2 \mathrm{~min}$ intervals. Subjects continued to breathe until unable to generate a threshold pressure sufficient to lift the plunger with two consecutive breaths. At this point inspiratory flow ceases and the subject is forced to stop. The maximum tolerated threshold pressure at this stage (P-Max) was taken as that which could be tolerated for a full two minute period. As endurance measures may relate to underlying muscle strength, P-Max was also expressed as a proportion of the maximum inspiratory pressure (MIP). This ratio provides a measure of inspiratory load. ${ }^{16-18} \mathrm{MIP}$ is an index of respiratory muscle strength and was measured from the best of three recordings once reproducible pressure plateaus were obtained. Measurements were made immediately before the endurance study at functional residual capacity using a flanged mouthpiece with a small leak connected to a pressure transducer (PK Morgan, Gillingham, Kent, UK). The total endurance test time and the number of $2 \mathrm{~min}$ stages $(\times 100 \mathrm{~g})$ completed were recorded. The study was repeated after a minimum rest period of $15 \mathrm{~min}$ and the longer of the two test times was used in subsequent analysis.

Repeat measurements of endurance were made in the patient group on the same day of the study to assess reproducibility. The mean (SD) difference in the number of $2 \mathrm{~min}$ endurance stages completed was $0.40(0.7)$; coefficient of repeatability $=1 \cdot 35$.

\section{LIMB MUSCLE STRENGTH}

Limb muscle strength was assessed by measuring grip strength in the dominant hand with a dynamometer. All subjects were seated with the elbow supported and the forearm horizontal. The best of three maximum contractions, sustained for $5 \mathrm{~s}$ with $5 \mathrm{~s}$ rest between were recorded.

\section{STATISTICS}

Results are expressed as mean (SD) unless otherwise specified. Statistical analysis was performed using standard non-parametric testing (Mann-Whitney $U$ test and Spearman's rank correlation) on the FASTAT microcomputer statistical package. The term "statistically significant" is reserved for $\mathrm{P}<$ $0 \cdot 05$.

\section{Results}

The mean age of the patients entering the study was similar to the controls $[63.8(7 \cdot 4) v$ $63 \cdot 1(5 \cdot 6)$ years, $P=N S]$. There were no significant differences in height $[1.71(0.05) v$ $1.76(0.08) \mathrm{m}]$ and weight $[77 \cdot 8(8.2) v 74 \cdot 7$ $(6.4) \mathrm{kg}$ ] between the two groups. The mean dose of frusemide in the patients studied was 89 (29) mg. Twelve of the patients were taking captopril [mean dose $94(24) \mathrm{mg}$ ] and eight patients enalapril [mean dose $17(6) \mathrm{mg}$ ].

The lung volumes of the patients studied are shown in table 1. Maximum inspiratory pressures were significantly reduced in the patients compared with the controls, at 53.6 (16.5) v $70.9(20.2) \mathrm{cm} \mathrm{H}_{2} \mathrm{O}, \mathrm{P}<0.05$. Hand grip strength in both the patients and controls was not significantly different, at $31.6(11.3) v$ 36.1 (15.9) dyn, $P=$ NS.

During assessment of endurance the mean number of stages were significantly lower in the patients compared with controls, at 3.8 $(2 \cdot 1)$ v $7.5(2 \cdot 1), \mathrm{P}<0.01$. Similarly the total test duration was lower in the patient group: 494 (223) $v 996$ (267) $\mathrm{s}, \mathrm{P}<0.01$ (fig 1). When the data were analysed according to NYHA grade there were trends towards a greater reduction in the endurance test duration in patients with more severe disease (table 2).

The maximum threshold pressure (P-Max) achieved was lower in the patients than in controls, at $18.5(6.4) v 30 \cdot 7(6 \cdot 6) \mathrm{cm} \mathrm{H}_{2} \mathrm{O}, \mathrm{P}<$ 0.01 (fig 2). When this was expressed as a percentage of maximum inspiratory pressure, $\mathrm{P}$ -

Table 1 Percentage predicted patient lung volumes

\begin{tabular}{lc}
\hline & \% Predicted (SD) \\
\hline FEV $_{1}$ & $79 \cdot 8(26)$ \\
FVC $_{\text {FEV }}$ /FVC & $83.7(19)$ \\
FRC $_{\text {RV }}$ & $67 \cdot 4(12)$ \\
TLC & $87 \cdot 2(24)$ \\
\hline
\end{tabular}

$\mathrm{FEV}_{1}$, forced expiratory volume in $1 \mathrm{~s} ; \mathrm{FVC}$, forced vital capacity; FRC, function residual capacity; RV, residual volume; TLC, total lung capacity. 


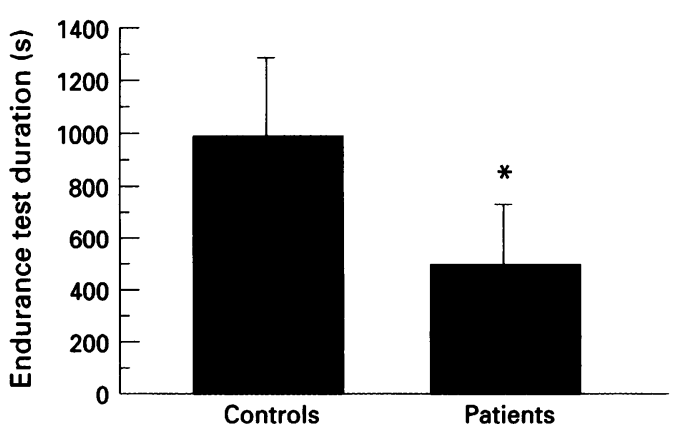

Figure 1 Total endurance duration in patients and controls. Values are means, bars $=S D .{ }^{\star} P<0.01$.

Table 2 Endurance test data analysed according to New York Heart Association (NYHA) grade. Values are mean (SD)

\begin{tabular}{lcc}
\hline & $\begin{array}{c}\text { NYHA II } \\
(n=11)\end{array}$ & $\begin{array}{l}\text { NYHA III/IV } \\
(n=9)\end{array}$ \\
\hline P-Max $\left(\mathrm{cm} \mathrm{H}_{2} \mathrm{O}\right)$ & $19 \cdot 9(5 \cdot 4)$ & $16 \cdot 8(7 \cdot 4)$ \\
P-Max $/ \mathrm{MIP} \%$ & $40 \cdot 2(11 \cdot 6)$ & $29 \cdot 2(9 \cdot 3)$ \\
Stages $(\times 100 \mathrm{~g})$ & $4 \cdot 3(1 \cdot 7)$ & $3 \cdot 2(2 \cdot 4)$ \\
Test duration $(\mathrm{s})$ & $538(206)$ & $441(251)$ \\
\hline
\end{tabular}

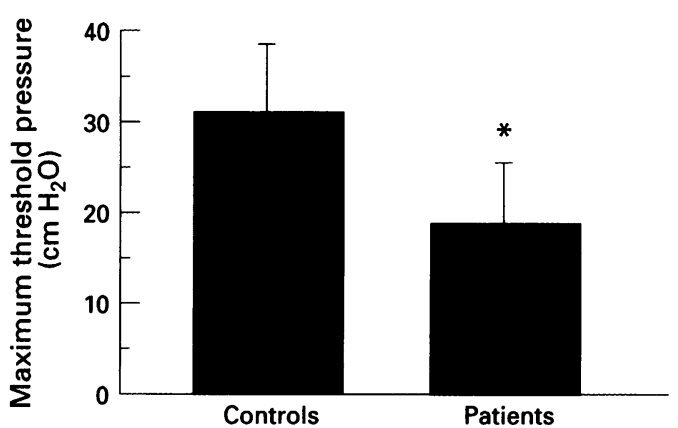

Figure 2 Maximum threshold pressure in patients and controls. Values are means, bars $=S D$. ${ }^{\star} P<0.01$.

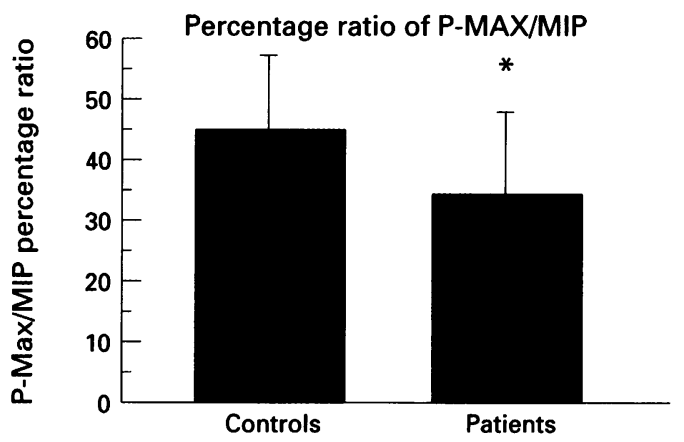

Figure 3 Maximum inspiratory load (P-Max/MIP\%) in patients and controls. Values are means, bars $=S D$. ${ }^{\star} P<0.05$.

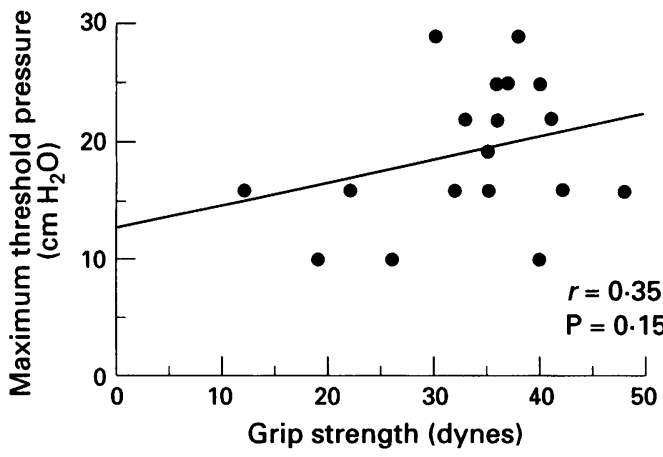

Figure 4 Relation between maximum threshold pressure and grip strength in patients with heart failure.
Max was also reduced in the patient group (fig 3). Similar trends were found when the data were analysed according to NYHA grade, with lower maximum threshold pressures seen in those with more severe disease (table 2). There was no significant correlation between the maximum threshold pressure achieved by the patients and measured hand grip strength (fig 4).

\section{Discussion}

We have shown that respiratory muscle endurance and strength is reduced in patients with chronic heart failure, even in those with mild to moderate disease. There were trends towards a greater reduction in endurance in those with more severe disease and this may in part explain the symptoms of fatigue and dyspnoea typically reported in this condition. These findings are compatible with a skeletal myopathic process described previously in this group of patients.

In our study a threshold loading technique was used for the first time to measure endurance in patients with heart failure. ${ }^{16-19}$ This offers several advantages over some of the other methods commonly described. Volume loading by isocapnic voluntary hyperpnoea has been used to assess patients with respiratory disease and in previous studies of patients with chronic heart failure. ${ }^{14} 1520$ This technique, however, requires expensive complex equipment and is susceptible to the effects of breathing frequency and underlying respiratory disease. ${ }^{16}$

By comparison the threshold loading method is a simple measure of respiratory muscle endurance, unaffected by breathing patterns, which provides an assessment of muscle function over time. ${ }^{1821}$ It is particularly useful for clinical studies as it is highly reproducible and a learning period appears unnecessary. ${ }^{17}$ The mechanisms of the device ensure a clear endpoint less dependent on motivation, as it requires the subject to generate a threshold pressure in order to initiate inspiratory flow and thus be able to breathe.

The technique we used is also less susceptible to the effects of underlying lung disease. ${ }^{16}$ This is important in studies of patients with heart failure, as obstructive, restrictive, and mixed airways abnormalities are well recognised. ${ }^{122-25}$ The reduction in $\mathrm{FEV}_{1}$ and FVC observed in our patients is previously described and probably reflects a degree of pulmonary congestion. Chronic pulmonary venous hypertension may also lead to interstitial fibrosis in patients with chronic heart failure. ${ }^{1122}$

Reduced muscle strength has been reported in patients with heart failure but there are few studies of respiratory muscle endurance. ${ }^{8-14}$ Exercise intolerance may reflect the inability of skeletal muscle to resist fatigue, that is, reduced endurance. The aetiology of these respiratory abnormalities at present is unclear but various mechanisms are proposed. These include impaired respiratory muscle perfusion due to a reduction in cardiac output ${ }^{10142627}$ 
and reduced respiratory muscle strength in association with a generalised myopathic process, particularly in patients with cardiac cachexia. ${ }^{28}$ In the patients we studied there was no history of significant weight loss, but the normal handgrip strength initially appears inconsistent with a generalised myopathy.

Measurement of handgrip strength, as opposed to forearm muscle endurance, represents a limitation to our study, as this technique was possibly insensitive to early myopathic changes. A lack of correlation between respiratory and limb muscle dysfunction has, however, been reported previously and the reasons for this are unclear. ${ }^{1213}$ It seems unlikely that a myopathic process should selectively involve the respiratory muscles and it has been proposed that this reflects a difference in the time course and magnitude of myopathic change between the respiratory and limb musculature. ${ }^{12}$ Our findings are compatible with this hypothesis and suggest that respiratory muscle dysfunction is an early and possibly more sensitive marker of skeletal myopathy in patients with heart failure.

Deconditioning due to inactivity may also be important in the myopathy of heart failure ${ }^{29}$ but this is unlikely to explain abnormalities of respiratory muscle function as the activity and work of breathing in these patients is often increased.$^{8}$ Even at rest minute ventilation is increased. ${ }^{22} 30$ Histochemical abnormalities are described in the diaphragmatic muscle of patients with chronic heart failure but it remains to be established whether these are the cause or effect of respiratory muscle dysfunction. ${ }^{31}$

Although we have confirmed reduced respiratory muscle endurance in patients with chronic heart failure, the significance of this in relation to exercise intolerance is unclear. Exertional dyspnoea and fatigue may be due to the combined effects of respiratory muscle dysfunction and increased respiratory muscle activity, as the work of breathing and the ventilatory response to exercise in patients with heart failure is increased. ${ }^{32}$ This increase in workload could exacerbate the effects of respiratory muscle dysfunction. In a recent small uncontrolled study of respiratory muscles in heart failure, improvements in endurance were associated with increased exercise capacity and reduced symptoms of dyspnoea during activities of daily living. ${ }^{14}$ Further studies are necessary to relate changes in endurance to exercise intolerance and patient symptom scores.

The effects of therapeutic intervention on respiratory muscle dysfunction in patients with heart failure are at present unknown. Inspiratory muscle training has been used in patients with respiratory disease ${ }^{33}$ and recently Mancini and coworkers demonstrated similar training effects in patients with heart failure. ${ }^{14}$ Cardiac transplantation ${ }^{34}$ and aerobic training $^{3536}$ reduce the excessive ventilatory response on exertion but their effects on muscle endurance have not been studied. Aminophylline, by improving diaphragmatic perfusion, might also prove beneficial. ${ }^{37}$

The results of this study have important implications for patients with chronic heart failure. They provide some insight into the possible mechanisms of exercise intolerance and confirm the presence of respiratory muscle dysfunction, even in those with mild to moderate disease. Measures of respiratory muscle strength have provided evidence of respiratory muscle dysfunction but measures of endurance are perhaps more relevant to the symptoms of chronic heart failure. Threshold loading of respiratory muscles is a simple technique suitable for clinical studies. The effects of treatment and respiratory muscle training on endurance should now be explored.

1 Franciosa JA, Park M, Levine B. Lack of relation between exercise capacity and indices of left ventricular performance in heart failure. Am $\mathcal{F}$ Cardiol 1981;47:33-9.

2 Cowley AJ. Are breathlessness and fatigue in chronic hear failure due to the same pathophysiological abnormality? Eur Heart F 1995;16:1-2.

3 Clark AL, Sparrow JL, Coats AJS. Muscle fatigue and dyspnoea in chronic heart failure: two sides of the same coin? Eur Heart $\mathcal{F}$ 1995;16:49-52.

4 Wilson JR. Exercise intolerance in heart failure. Importance of skeletal muscle. Circulation 1995;91:559-61.

5 Minotti JR, Christoph I, Oka R, Weiner MW, Wells L, Massie BM. Impaired skeletal muscle function in patients with congestive heart failure. $\mathcal{F}$ Clin Invest. 1991; 88:2077-82.

6 Wilson JR, Mancini DM, Dunkman WR. Exertional fatigue due to skeletal muscle dysfunction in patients with heart failure. Circulation 1993;87:470-5.

7 Massie BM, Conway M, Yonge R, Frostick S, Ledingham J. Skeletal muscle metabolism during exercise under ischaemic conditions in congestive cardiac failure. Circulation 1988;78:320-6.

8 Mancini DM, Henson D, La Manca J, Levine S. Respiratory muscle function and dyspnoea in patients with chronic congestive heart failure. Circulation 1992;86: 909-18.

9 McParland C, Krishnan B, Wang B, Gallagher CG Inspiratory muscle weakness and dyspnoea in chronic heart failure. Am Rev Respir Dis 1992;146:467-72.

10 Nishimura Y, Maeda H, Tanaka K, Nakamura H, Hasimoto Y, Yokoyama M. Respiratory muscle strength and haemodynamics in chronic heart failure. Chest 1994; 105:355-9.

11 Ambrosino N, Opasich C, Crotti P, Cobelli F, Tavazzi L, Rampulla C. Breathing pattern, ventilatory drive and respiratory muscle strength in patients with chronic hear failure. Eur Resp f 1994;7:17-22.

12 Chua TP, Anker SD, Harrington D, Coats AJS. Inspiratory muscle strength is a determinant of maximum oxygen consumption in chronic heart failure. Br Heart 71995 74:381-5.

13 Hammond M, Bauer K, Sharp J, Rocha R. Respiratory muscle strength in congestive heart failure. Chest 1990; 98:1091-4.

14 Mancini DM, Henson D, La Manca J, Donchez L, Levine $\mathrm{S}$. Benefit of selective respiratory muscle training on exercise capacity in patients with chronic congestive heart cise capacity in patients with chron
failure. Circulation 1995;91:320-9.

15 Mancini DM, LaManca J, Levine S, Henson D Respiratory muscle endurance is decreased in patients with heart failure. Circulation 1992:86(suppl I):I-515.

16 Nickerson BG, Keens TG. Measuring ventilatory muscle endurance in humans as sustainable inspiratory pressure. f Appl Physiol 1982;52:768-72.

17 McElvaney G, Fairbarn MS, Wilcox PG, Pardy RL Comparison of two-minute incremental threshold loading and maximal loading as measures of respiratory muscle endurance. Chest 1989;96:557-63.

18 Martyn JB, Moreno RH, Pare PD, Pardy RI Measurement of inspiratory muscle performance with Measurement of inspiratory muscle performance with
incremental threshold loading. Am Rev Respir Dis 1987;

19 Eastwood PR, Hillman DR. A threshold loading device for testing of inspiratory muscle performance. Eur Respir $\mathcal{F}$ 1995;8:463-6.

20 Bai TR, Rabinovitch BJ, Pardy RL. Near maximal voluntary hyperpnoea and ventilatory muscle function. $\mathcal{F} A p p$ Physiol 1984:57:1742-8.

21 Morrison NJ, Fairbarn MS, Pardy RL. The effect of breathing frequency on respiratory muscle endurance using incremental threshold loading. Am Rev Respir Dis 1988:137:163.

22 Chua TP, Coats AJS. The lungs in chronic heart failure. Eur Heart F 1995;16:882-7.

23 Petermann W, Barth J, Entzian P. Heart function and airway obstruction. Int $\mathcal{f}$ Cardiol 1987;17:207-9.

24 Faggiano P, Lombardi C, Sorgato A, Ghizzoni G, Spedini C, Rusconi C. Pulmonary function tests in patients with congestive heart failure: effects of medical therapy. Cardiology 1993:83:30-5.

25 Ries AL, Gregoratos G, Friedman PJ, Clausen JL 
Pulmonary function tests in the detection of left heart failure: correlation with pulmonary artery wedge pressure. Respiration 1986;49:241-50.

26 Aubier M, Trippenbach T, Rousso C. Respiratory muscle fatigue during cardiogenic shock. $\mathcal{f}$ Appl Physiol 1981;51: 499-508.

27 Mancini DM, Ferraro N, Nazzaro D, Chance B, Wilson JR. Respiratory muscle deoxygenation during exercise in patients with heart failure demonstrated with near infraread spectroscopy. F Am Coll Cardiol 1991;18:492-8. 28 Editorial. Skeletal muscle in heart failure. Lancet 1992; 340:1383-4. 29 Gibson JNA, Morrison WL, Halliday D, Steward PJ, ceps muscle protein turnover consequent upon leg immobilisation. Clin Sci 1987;72:503-9.

30 Cowley AJ, Stainer K, Rowley JM, Hampton JR. Abnormalities of the peripheral circulation and respiratory function in patients with severe heart failure. $\mathrm{Br}$ tory function in patien

31 Lindsay DC, Lovegrove CA, Dunn MJ, Bennett JG, Pepper JR, Yacoub MH, et al. Histological abnormalities of diaphragmatic muscle may contribute to dyspnoea in heart failure. Circulation 1992;86(suppl I):I-514

32 Sullivan $M$, Higginbotham $M$, Cobb F. Increased exercise ventilation in patients with chronic heart failure: intact ventilatory control despite haemodynamic and pulventilatory control despite haemodynamic and

33 Gosselink R, Decramer M. Inspiratory muscle training where are we ? Eur Respir f 1994;7:2103-5.

34 Marzo KP, Wilson JR, Mancini DM. Effects of cardiac transplantation on ventilatory response to exercise. $A m \mathcal{F}$ Cardiol 1992;69:547-53.

35 Coats AJS, Adampoulos S, Radaelli A, McCance A, Meyer $\mathrm{T}$, Bernardi $\mathrm{L}$, et al. Controlled trial of physical training in chronic heart failure. Circulation 1992;85:2119-31.

36 Sullivan M, Higginbotham M, Cobb F. Exercise training in patients with chronic heart failure delays ventilatory anaerobic threshold and improves submaximal exercise performance. Circulation 1989;79:324-9.

37 Murciano D, Aubier M, Le Cocquie Y, Pariente R. Effects of theophylline on diaphragmatic strength and fatigue in patients with chronic obstructive pulmonary disease. $N$ Engl F Med 1984;311:349-53. 